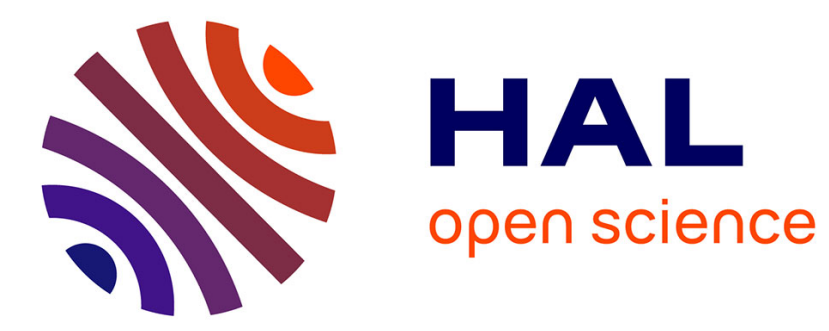

\title{
New insight in the uranium valence state determination in $\mathbf{U} \_y \mathbf{N d} \_1--y \mathbf{O} \_2 \pm x$
}

\author{
R. Bès, K. Kvashnina, A. Rossberg, G. Dottavio, L. Desgranges, Yves \\ Pontillon, P.L. Solari, S. M Butorin, P. Martin
}

\section{- To cite this version:}

R. Bès, K. Kvashnina, A. Rossberg, G. Dottavio, L. Desgranges, et al.. New insight in the uranium valence state determination in $\mathrm{U} \_y \mathrm{Nd} \_1--y \mathrm{O} \_2 \pm x$. Journal of Nuclear Materials, 2018, 507, pp.145-150. 10.1016/j.jnucmat.2018.04.046 . cea-02429995

\section{HAL Id: cea-02429995 https://hal-cea.archives-ouvertes.fr/cea-02429995}

Submitted on 7 Jan 2020

HAL is a multi-disciplinary open access archive for the deposit and dissemination of scientific research documents, whether they are published or not. The documents may come from teaching and research institutions in France or abroad, or from public or private research centers.
L'archive ouverte pluridisciplinaire HAL, est destinée au dépôt et à la diffusion de documents scientifiques de niveau recherche, publiés ou non, émanant des établissements d'enseignement et de recherche français ou étrangers, des laboratoires publics ou privés. 


\title{
New insight in the uranium valence state determination in $\mathrm{U}_{y} \mathrm{Nd}_{1-y} \mathrm{O}_{2 \pm x}$
}

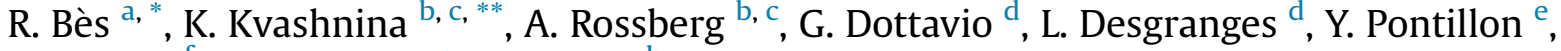 \\ P.L. Solari ${ }^{\mathrm{f}}$, S.M. Butorin ${ }^{\mathrm{g}}$, P. Martin ${ }^{\mathrm{h}}$ \\ ${ }^{a}$ Department of Applied Physics, Aalto University, P.O. Box 14100, FI-00076 Aalto, Finland \\ ${ }^{\mathrm{b}}$ Rossendorf Beamline at ESRF - The European Synchrotron, CS40220, 38043 Grenoble Cedex 9, France \\ ${ }^{c}$ Helmholtz Zentrum Dresden-Rossendorf (HZDR), Institute of Resource Ecology, P.O. Box 510119, 01314 Dresden, Germany \\ ${ }^{d}$ CEA, DEN, DEC, F-13108 Saint Paul Lez Durance Cedex, France \\ e CEA/DEN/CAD/DEC/SA3C/LAMIR, Saint Paul lez Durance, France \\ ${ }^{f}$ Synchrotron SOLEIL, Ligne de Lumière MARS, L'Orme des Merisiers, Saint Aubin, BP 48, F-91192 Gif-sur-Yvette Cedex, France \\ ${ }^{g}$ Molecular and Condensed Matter Physics, Department of Physics and Astronomy, Uppsala University, P.O. Box 516, SE-751 20 Uppsala, Sweden \\ ${ }^{\mathrm{h}}$ CEA, Nuclear Energy Division, Research Department on Mining and Fuel Recycling Process, SFMA/LCC, Bagnols-sur-Cèze, France
}

\section{A R T I C L E I N F O}

\section{Article history:}

Received 12 October 2017

Received in revised form

30 April 2018

Accepted 30 April 2018

Available online 3 May 2018

\begin{abstract}
A B S T R A C T
The charge compensation mechanisms in $\mathrm{U}_{y} \mathrm{Nd}_{1-y} \mathrm{O}_{2 \pm x}$ and its consequence on the overall $\mathrm{O}$ stoichiometry (or $\mathrm{O} / \mathrm{M}$ ratio where $\mathrm{M}=\mathrm{Nd}+\mathrm{U}$ ) have been studied through the uranium valence state mixture evolution as a function of $\mathrm{Nd}$ content up to $\mathrm{y}=0.62$ by means of high energy resolution fluorescence detection X-ray absorption spectroscopy (HERFD-XAS) at the $\mathrm{U} \mathrm{M}_{4}$-edge. Our results clearly demonstrate the formation of $\mathrm{U}^{5+}$ at low $\mathrm{Nd}$ content $(\mathrm{y}<0.15)$. Upon increasing the $\mathrm{Nd}$ content, oxygen vacancies and the formation of $\mathrm{U}^{6+}$ appear as competing mechanisms for intermediate Nd concentrations, leading to the co-existence of $\mathrm{U}^{4+} / \mathrm{U}^{5+} / \mathrm{U}^{6+}$ mixed valence and an overall hypostoichiometry $(\mathrm{O} / \mathrm{M}<2.00)$. Finally, the formation of $U^{6+}$ associated with strongly distorted $U$ local environment is observed for high $\mathrm{Nd}$ concentrations $(y=0.62)$, leading to an overall hyperstoichiometry $(O / M<2.00)$.
\end{abstract}

() 2018 Elsevier B.V. All rights reserved.

\section{Introduction}

For many decades, uranium oxide, $\mathrm{UO}_{2}$, has been used as fuel in nuclear power plants. Among the non-volatile fission products created during in-pile irradiation, lanthanides (Ln) represent approximately 35 weight $\%$ of the inventory [1]. These elements are known to be soluble in the $\mathrm{UO}_{2}$ structure and to form a solid solution over a wide range of composition $(\mathrm{U}, \mathrm{Ln}) \mathrm{O}_{2 \pm x}$ [2], but lattice parameters change depending on the irradiation conditions [3-6]. The existence of such solid solutions is expected to be correlated to uranium valence states flexibility (from $\mathrm{U}^{4+}$ to $\mathrm{U}^{5+}$ and $\mathrm{U}^{6+}$ ) and to the formation of oxygen vacancies, which both ensure the charge neutrality [7]. Nevertheless, recent studies have demonstrated the

\footnotetext{
* Corresponding author.

** Corresponding author. Rossendorf Beamline at ESRF - The European Synchrotron, CS40220, 38043 Grenoble Cedex 9, France.

E-mail addresses: rene.bes@aalto.fi (R. Bès), kristina.kvashnina@esrf.fr (K. Kvashnina).
}

existence of a miscibility gap at room temperature for samples containing higher than 3 at. \% of $\mathrm{Nd}$ [8-10]. In these studies, high temperature X-ray diffraction (XRD) measurements as well as Raman spectroscopy have highlighted the coexistence of two face centered cubic (FCC) phases exhibiting different oxygen stoichiometry or $\mathrm{O} / \mathrm{M}$ ratio $(\mathrm{M}=\mathrm{U}+\mathrm{Nd}$ ) leading to the general formulas $\mathrm{U}_{y} \mathrm{Nd}_{1-y} \mathrm{O}_{2 \pm x}$ and $\mathrm{U}_{y} \mathrm{Nd}_{1-y} \mathrm{O}_{2.00}$. The miscibility gap appears to be stable up to $745-800 \mathrm{~K}$ [9]. For higher temperatures, only one $\mathrm{U}_{y} \mathrm{Nd}_{1-y} \mathrm{O}_{2-x}$ phase is present. In $\mathrm{U}_{y} \mathrm{Pu}_{1-y} \mathrm{O}_{2-x}$ [11] and $\mathrm{U}_{y} \mathrm{Ce}_{1-y} \mathrm{O}_{2-x}$ [12] systems, a miscibility gap also exists for $\mathrm{y}>0.2$, with the coexistence of oxygen vacancy and uranium valence states $\mathrm{U}^{5+}$ for an overall hypostoichiometric formula $(\mathrm{O} / \mathrm{M}<2)$. However, such coexistence in $\mathrm{U}_{y} \mathrm{Nd}_{1-y} \mathrm{O}_{2 \pm x}$ remains an open question since no clear experimental evidence is reported in the literature.

X-ray absorption spectroscopy (XAS) is particularly advantageous to probe the electronic structure and the local structure of actinide materials by means of X-ray absorption near the edge structure (XANES) and the extended X-ray absorption fine structure (EXAFS). In addition, the penetrating nature of X-rays in the 
3-20 keV energy range, that is, actinide's $\mathrm{M}_{4,5^{-}}$and $\mathrm{L}_{3}$-edges, allows us to analyze confined samples, avoiding risks of radionuclide dispersion; also, the use of synchrotron radiation limits the masses of the samples that are investigated [13]. However, considering the broadening of XANES spectra due to core-hole lifetime effects, the observation of very fine details can be limited. Thanks to the recent development of X-ray emission spectroscopy, one can directly probe the $5 \mathrm{f}$ and $6 \mathrm{~d}$ electron density of states and local structure with a virtually reduced core-hole lifetime broadening. This approach, high energy resolution fluorescence detected-XAS (HERFD-XAS), allows highly precise determination of electronic and local structures of actinides, including direct evaluation of valence state mixtures [14]. For example, this approach has been successfully applied to $(\mathrm{U}, \mathrm{Bi}) \mathrm{O}_{2}$ mixed oxides [15].

However, the most used $\mathrm{U} \mathrm{L}_{3}$-edge XANES can also be strongly affected by the local geometry [16,17]. One major difficulty is often the unavailability of reference compounds with both the correct symmetry and the same valence. Indeed, an incorrect valence state mixture evaluation using, for example, linear combination fitting is generally the consequence of changes in local symmetry which can induce pre-edge peaks or resonances. Their presence or absence in reference spectra compared to the studied sample spectra would subsequently affect the fitting results. The best example is uranyllike bonding and its spectral features. More precisely, in uranyllike bonding containing compounds, both intensities and energy positions are affected by the U-O bonding distance as described by Podkovyrina et al. [18]. Therefore, reference compounds must be chosen wisely, taking into account the presence or lack of a specific spectral feature on the studied compounds, especially when these features strongly contribute to the fitted portion of the spectrum. However, $\mathrm{U}_{\mathrm{L}_{3}}$-edge changes remain limited, and linear combination fitting has given accurate results for mixed actinides, such as $(\mathrm{U}, \mathrm{Am}) \mathrm{O}_{2}$ and $(\mathrm{U}, \mathrm{Pu}) \mathrm{O}_{2}$ in deducing the overall actinides valence and the oxygen stoichiometry of the samples [19-24].

By taking advantage of the HERFD-XAS capability, this paper aims to provide accurate $\mathrm{U}$ valence state evaluation on $\mathrm{U}_{y} \mathrm{Nd}_{1-y} \mathrm{O}_{2 \pm x}$ samples as a function of $\mathrm{Nd}$ content. Such key knowledge would reveal important insights about $\mathrm{O} / \mathrm{M}$ ratio behavior and is discussed here through electroneutrality and the associated charge compensation mechanisms.

\section{Material and experimental methods}

\subsection{Sample preparation}

The $\mathrm{U}_{y} \mathrm{Nd}_{1-y} \mathrm{O}_{2 \pm x}$ samples were prepared by homogeneously mixing $\mathrm{Nd}_{2} \mathrm{O}_{3}$ and $\mathrm{UO}_{2}$ powders with targeted $\mathrm{Nd} /(\mathrm{U}+\mathrm{Nd})$ ratios. The sample compositions are given in Table 1 . The powders were pressed at $450 \mathrm{MPa}$ and sintered over $72 \mathrm{~h}$ in a reductive atmosphere (dry $\mathrm{Ar}+5 \% \mathrm{H}_{2}$ ) at $1973 \mathrm{~K}$. Subsequent room temperature Xray diffraction characterization showed that the final pellets are free of $\mathrm{Nd}_{2} \mathrm{O}_{3}$ precipitates [8]. To limit oxidation/hydration process during sample storage, the pellets were confined between two glued $12.5 \mu \mathrm{m}$ kapton foils.

\subsection{X-ray absorption spectroscopy}

The $\mathrm{U}_{2}$-edge XANES measurements were carried out at the MARS beamline [25] located at SOLEIL, the French synchrotron at Saint-Aubin, France. The photon energy was scanned from 17100 to $17300 \mathrm{eV}$, using the $\mathrm{Si}(220)$ sagittal focusing double-crystal monochromator (DCM). Rejection of higher harmonics as well as vertical collimation/focusing was achieved by two platinum-coated mirrors, placed before and after the DCM, working under total reflection at $3.1 \mathrm{mrad}$. The beam size was estimated to be about $0.3 \mathrm{~mm}$ both vertically and horizontally. Energy calibration was achieved using the first inflection point of XANES spectra collected at the Y K-edge $(17038 \mathrm{eV})$ of an yttrium metal foil. The XANES spectra were collected in fluorescence mode at room temperature using a Vortex-90-EX silicon drift detector. Both dead time and potential saturation/pile-up of the detector were minimized by optimizing sample-detector distance and by using Al foils as an attenuator to cut fluorescence lines at energies below $13 \mathrm{keV}$. The total energy resolution is estimated to be about $8.3 \mathrm{eV}$.

The $\mathrm{U} \mathrm{M}_{4}$-edge XANES measurements were performed at the ID26 beamline [26] of the ESRF - the European synchrotron at Grenoble, France. The $\mathrm{U} \mathrm{M}_{4}$-edge incident energy (3725 eV) was selected using the $\mathrm{Si}(111)$ double crystal monochromator. Three $\mathrm{Si}$ mirrors at 3.5 mrad working under total reflection achieved rejection of higher harmonics. The beam size was estimated to be about $0.2 \mathrm{~mm}$ vertically and $0.4 \mathrm{~mm}$ horizontally. HERFD-XANES spectra were measured using an X-ray emission spectrometer equipped with five $\mathrm{Si}(220)$ crystal analyzers and a silicon drift diode in a vertical Rowland geometry [27]. The spectrometer was tuned to the maximum of the $U \mathrm{M}_{\beta}\left(3 \mathrm{~d}_{3 / 2}-4 \mathrm{f}_{5 / 2}, 3337 \mathrm{eV}\right) \mathrm{X}$-ray emission line using the (220) reflection of the $\mathrm{Si}$ analyzer crystals at a Bragg angle of $75.4^{\circ}$. The detected intensity was normalized to the incident flux. A combined (incident convoluted to emitted) energy resolution of $0.4 \mathrm{eV}$ was obtained as determined by measuring the full width at half maximum (FWHM) of the elastic scattering peak measured at $3337 \mathrm{eV}$ on a W foil.

The experiments reported here were performed at room temperature in ambient air without any additional environment around the sample. The paths of the incident and emitted X-rays through air during the experiments were minimized using a specially designed He bag to avoid losses in intensity due to absorption in the air.

ATHENA software [28] was used for normalizing XANES spectra from the raw absorption data. Pre-edge removal and normalization were achieved using linear functions at the $\mathrm{U} \mathrm{L}_{3}$-edge. $\mathrm{U} \mathrm{M}_{4}$-edge spectra were normalized with respect to their maximum. The energy threshold $\left(E_{0}\right)$ values were chosen as the first inflection point of the first derivative relative to the incident energy. In addition, the white-line maximum energy values were deduced from the first inflection point of the same derivatives.

The iterative target test (ITT) associated to the Factor Analysis as available within the ITFA code [29] has been used to extract the uranium valence concentrations $\left(\left[\mathrm{U}^{4+}\right],\left[\mathrm{U}^{5+}\right]\right.$ and $\left.\left[\mathrm{U}^{6+}\right]\right)$ from HERFD spectra. Such a procedure does use principal component analysis as a first step, then the ITT finds the relative concentration

Table 1

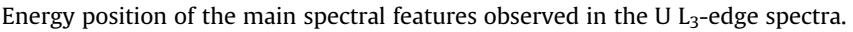

\begin{tabular}{|c|c|c|c|c|}
\hline Sample & $\mathrm{E}_{0}(\mathrm{eV})$ & White line $(\mathrm{eV})$ & Shoulder (eV) & Resonance $(\mathrm{eV})$ \\
\hline $\mathrm{UO}_{2}$ & $17169.0(5)$ & $17175.0(5)$ & $17188.3(5)$ & $17212.9(5)$ \\
\hline $\mathrm{U}_{0.91} \mathrm{Nd}_{0.09} \mathrm{O}_{2 \pm x}$ & $17169.7(5)$ & $17175.3(5)$ & $17188.5(5)$ & $17213.6(5)$ \\
\hline $\mathrm{U}_{0.85} \mathrm{Nd}_{0.15} \mathrm{O}_{2 \pm x}$ & $17169.9(5)$ & $17175.4(5)$ & $17188.6(5)$ & 17213.5 \\
\hline $\mathrm{U}_{0.71} \mathrm{Nd}_{0.29} \mathrm{O}_{2 \pm x}$ & $17170.0(5)$ & $17175.9(5)$ & $17188.4(5)$ & $17214.5(5)$ \\
\hline $\mathrm{U}_{0.38} \mathrm{Nd}_{0.62} \mathrm{O}_{2 \pm x}$ & $17172.8(5)$ & $17179.0(5)$ & - & $17224.8(5)$ \\
\hline
\end{tabular}


of the deduced principal components. In our case, three components were contributing to the spectrum and are sufficient to reproduce the spectra well. The other components have no significant contributions and were discarded. The three considered components were attributed to $\mathrm{U}^{4+}, \mathrm{U}^{5+}$ and $\mathrm{U}^{6+} . \mathrm{UO}_{2}, \mathrm{NaUO}_{3}$ and $\beta-\mathrm{UO}_{3}$ were used as pure representatives for $\mathrm{U}^{4+}, \mathrm{U}^{5+}$ and $\mathrm{U}^{6+}$ respectively, and so, their values were guessed to $100 \%$ and/or $0 \%$. They were left totally free for the $\mathrm{U}_{y} \mathrm{Nd}_{1-y} \mathrm{O}_{2 \pm x}$ samples.

\section{Experimental results and discussion}

The uranium $\mathrm{L}_{3}$-edge XANES spectra of $\mathrm{U}_{y} \mathrm{Nd}_{1-y} \mathrm{O}_{2 \pm x}$ samples are reported in Fig. 1.

The $\mathrm{UO}_{2}$ XANES spectrum exhibits an intense peak, the so-called white line (WL) situated at $17175.0(5) \mathrm{eV}$, and one additional resonance at higher energy (around 17212.9 (5) eV), at the transition to the EXAFS region. A shoulder on the right side of the WL is also observed at 17188.3 (5) eV. The inflection point, $\mathrm{E}_{0}$, was found at 17169.0 (5) eV. The corresponding values for the $\mathrm{Nd}$ doped samples are reported in Table 1.

Except for the $\mathrm{U}_{0.38} \mathrm{Nd}_{0.62} \mathrm{O}_{2 \pm x}$ sample, all the $\mathrm{Nd}$ doped $\mathrm{UO}_{2}$ samples show spectral features close to $\mathrm{UO}_{2}$. The uranium local environment is clearly maintained in the uranium rich region up to $y=0.29$. A slight shift toward high energy is observed for $E_{0}$. In addition, the WL intensity decreases and the intensity of the shoulder increases simultaneously upon increasing the Nd content. A similar behavior was observed in $\mathrm{U}_{1-y} \mathrm{Gd}_{y} \mathrm{O}_{2}$ [30] and in $\mathrm{U}_{1-y} \mathrm{Am}_{y} \mathrm{O}_{2}[21,22,24]$ samples where Am was purely trivalent. It is attributed to the formation of $\mathrm{U}^{5+}$ as charge compensation mechanism in both $\mathrm{U}_{1-y} \mathrm{Gd}_{y} \mathrm{O}_{2}$ and $\mathrm{U}_{1-y} \mathrm{Am}_{y} \mathrm{O}_{2}$.

Strong changes in uranium local environment have to be expected in the $\mathrm{Nd}$ rich region. Indeed, the overall shape of the $\mathrm{U}_{0.38} \mathrm{Nd}_{0.62} \mathrm{O}_{2 \pm x}$ spectrum is quite different from that of $\mathrm{UO}_{2}$. Moreover, a shift of about $3.8 \mathrm{eV}$ towards higher energies is observed for $E_{0}$. Both shift and absence of intensity around $17169 \mathrm{keV}$, that is, at the $\mathrm{E}_{0}$ energy position corresponding to $\mathrm{U}^{4+}$, are insights of probable absence of $\mathrm{U}^{4+}$ on the sample. As previously explained, the $\mathrm{U}_{\mathrm{L}_{3}}$-edge is strongly affected by the local geometry around $U$ atoms and the presence of a quadrupole transition, both potentially leading to incorrect evaluation of valence states mixtures. Then, the use of reference compounds must follow the following informal rule: the closer the local

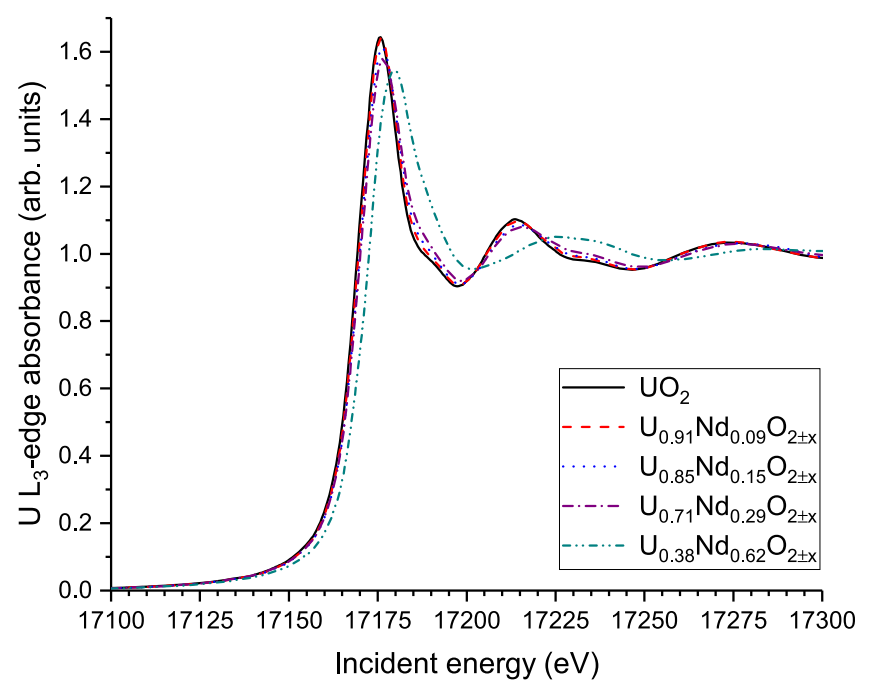

Fig. 1. Uranium $\mathrm{L}_{3}$-edge XANES experimental spectra recorded on $\mathrm{UO}_{2}$ and $\mathrm{U}_{y} \mathrm{Nd}_{1-y} \mathrm{O}_{2 \pm x}$ samples as collected at MARS beamline. environment is, the most accurate are the valence state ratios. However, no face centered cubic phases are reported with pure $\mathrm{U}^{5+}$ and $\mathrm{U}^{6+}$ valence states. Therefore, one has to find another way to extract accurate quantitative valence state ratios. At the $\mathrm{U} \mathrm{M}_{4,5^{-}}$ edge HERFD-XANES spectra, shifts due to the presence of oxidation states higher than $\mathrm{U}^{4+}$ are better resolved than for $\mathrm{U}_{3}$-edge and spectra generally show similar shapes for different local environments when uranyl-like bonding is not involved [14,18,31-34]. Hence, a $\mathrm{U} \mathrm{M}_{4,5}$-edge appears to be the best choice in that case.

The uranium $\mathrm{M}_{4}$-edge HERFD-XANES spectra of $\mathrm{U}_{1-y} \mathrm{Nd}_{y} \mathrm{O}_{2 \pm x}$ samples are reported in Fig. 2. They are compared to the reference spectra of $\mathrm{UO}_{2}, \mathrm{NaUO}_{3}$ and $\beta-\mathrm{UO}_{3}$. These stoichiometric and singlephase reference compounds correspond to pure $\mathrm{U}^{4+}, \mathrm{U}^{5+}$ and $\mathrm{U}^{6+}$ valence states, respectively.

As expected, all the $\mathrm{Nd}$ doped $\mathrm{UO}_{2}$ samples, except $\mathrm{U}_{0.38} \mathrm{Nd}_{0.62} \mathrm{O}_{2 \pm x}$, show spectral features close to $\mathrm{UO}_{2}$, confirming the previous conclusions at $\mathrm{U} \mathrm{L}_{3}$-edge, but the $\mathrm{U}^{5+} / \mathrm{U}^{6+}$ contributions are here more clearly identified. The corresponding spectral feature energy positions are reported in Table 2.

The increasing intensity of the shoulder at the high energy side of the $\mathrm{U}^{4+} \mathrm{WL}$ indicates the formation of $\mathrm{U}^{5+}$ and/or $\mathrm{U}^{6+}$ valence states $[14,31,32]$. The $\mathrm{U}_{0.38} \mathrm{Nd}_{0.62} \mathrm{O}_{2 \pm x}$ sample does not show any $\mathrm{U}^{4+}$ feature and is most probably composed by a mixture of $\mathrm{U}^{5+}$ and $\mathrm{U}^{6+}$ only, even if its spectrum is dominated by $\mathrm{U}^{6+}$ WL. The factor analysis reconstructed spectra are shown in Fig. 2. An overall agreement between the experimental spectra and the reconstructed spectra using the three principal components is obtained, except for the $\mathrm{Nd}$ rich sample and $\beta-\mathrm{UO}_{3}$. This is the consequence of very different local symmetry around $U$ one can expect comparing $\mathrm{NaUO}_{3}, \beta-\mathrm{UO}_{3}$ and the structure one can expect for very high $\mathrm{Nd}$ content. However, the fit results confirm that the $\mathrm{U}^{6+}$ valence state is predominant in that case. The deduced valence concentrations $\left[\mathrm{U}^{4+}\right],\left[\mathrm{U}^{5+}\right]$ and $\left[\mathrm{U}^{6+}\right]$ are drawn as a function of the Nd content in Fig. 3 and are reported in Table 3.

In the U-rich region, i.e. for low $\mathrm{Nd}$ contents, there is no $\mathrm{U}^{6+}$, but only $\mathrm{U}^{5+}$. In the Nd-rich region, both $\mathrm{U}^{5+}$ and $\mathrm{U}^{6+}$ are formed, and $\mathrm{U}^{4+}$ is no more observed. In Fig. 3, the measured uranium valence state concentrations are compared with two different compensation models to understand the underlying mechanisms involved in the charge compensation when adding trivalent atoms in $\mathrm{UO}_{2}$. The first model, called Model \#1, corresponds to the formation of $\mathrm{U}^{5+}$. The second one, Model \#2, is based on the formation of $U^{6+}$. Both models keep stoichiometry, with no deviation from $\mathrm{O} / \mathrm{M}=2.00$ as $\left[\mathrm{U}^{5+}\right]=\left[\mathrm{Nd}^{3+}\right]$ and $\left[\mathrm{U}^{6+}\right]=2^{*}\left[\mathrm{Nd}^{3+}\right]$, respectively. An additional compensation mechanism would be the formation of oxygen vacancies $\mathrm{V}_{O}$, and is called Model \#3. This model leads to no change in the uranium valence concentration and thus does not appear in Fig. 3. However, Model \#3 directly affects the global O/M ratio by reducing the oxygen content by $\mathrm{y} / 2$ and leads to an overall hypostoichiometry, that could be associated to the reported miscibility gap through the presence of its hypostoichiometric phase.

These three models obey the following equations:

(1)Model \#1: $(1-2 y) U^{4+}+y U^{5+}+y N d^{3+}$

(2)Model \#2: $\left(1-\frac{3 y}{2}\right) U^{4+}+\frac{y}{2} U^{6+}+y N d^{3+}$

(3)Model \#3: $(1-y) U^{4+}+\frac{y}{2} V_{O}+y N d^{3+}$

Below $y=0.2$, the results are in very good agreement with Model \#1, suggesting a unique compensation mechanism via the formation of $\mathrm{U}^{5+}$ only, and stoichiometric samples, that is, $\mathrm{y}=0$. This result is perfectly in line with the values reported by Dottavio 

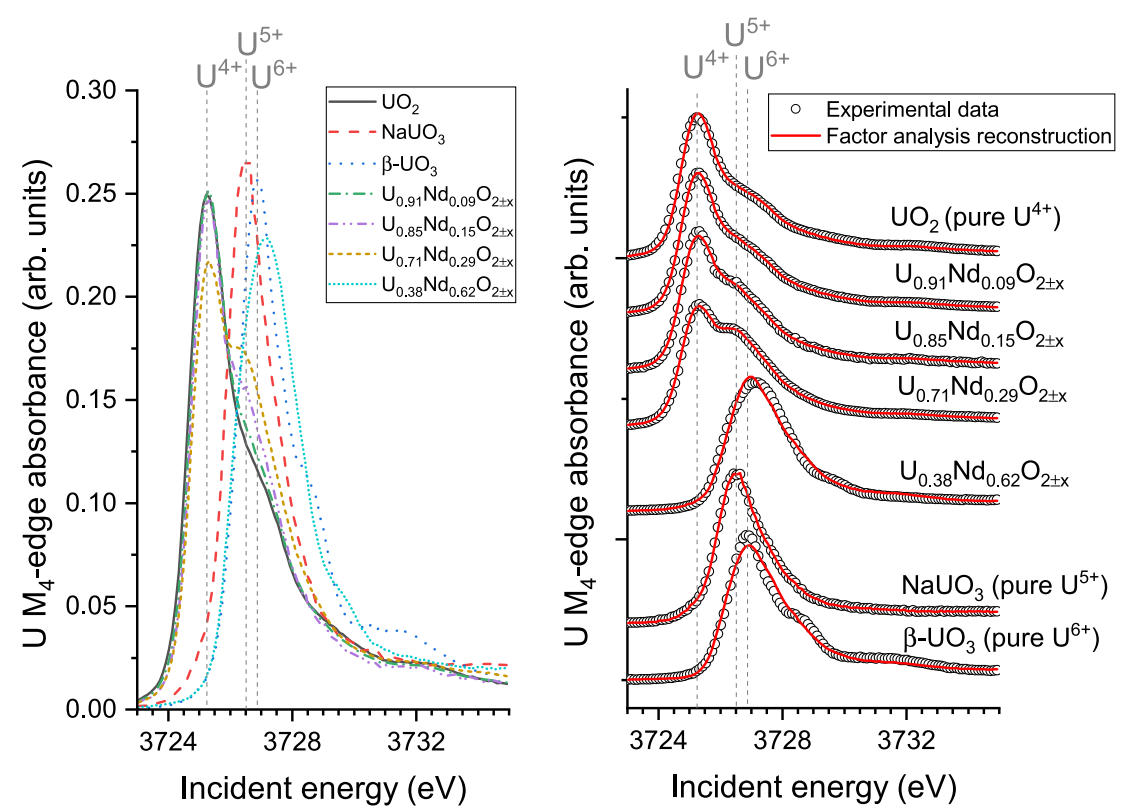

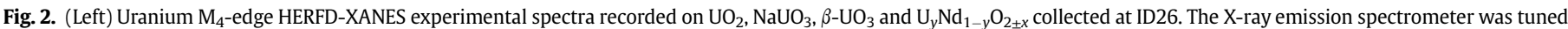

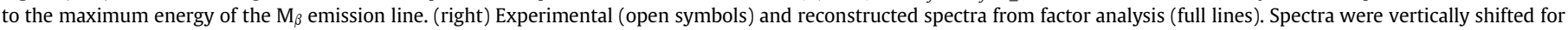
sake of clarity.

Table 2

Overview and comparison to literature data of incident energy at the white-line position for the studied samples as indicated in Fig. 2.

\begin{tabular}{|c|c|c|c|c|}
\hline \multirow[t]{2}{*}{ Sample } & \multicolumn{3}{|c|}{ White line (eV) } & \multirow[t]{2}{*}{ Reference } \\
\hline & $\mathrm{U}^{4+}$ & $\mathrm{U}^{5+}$ & $\mathrm{U}^{6+}$ & \\
\hline $\mathrm{UO}_{2}$ & $3725.3(2)$ & - & - & This work \\
\hline $\mathrm{UO}_{2}$ & $3725.5(2)$ & - & - & [32] \\
\hline $\mathrm{NaUO}_{3}$ & - & $3726.6(2)$ & - & This work \\
\hline $\mathrm{KUO}_{3}$ & - & $3726.4(2)$ & - & [32] \\
\hline$\beta-\mathrm{UO}_{3}$ & - & - & $3726.9(2)$ & This work \\
\hline$\beta-\mathrm{UO}_{3}$ & - & - & $3726.8(2)$ & [32] \\
\hline $\mathrm{U}_{0.91} \mathrm{Nd}_{0.09} \mathrm{O}_{2 \pm x}$ & $3725.3(2)$ & $3726.6(2)$ & - & This work \\
\hline $\mathrm{U}_{0.85} \mathrm{Nd}_{0.15} \mathrm{O}_{2 \pm x}$ & $3725.3(2)$ & $3726.5(2)$ & - & This work \\
\hline $\mathrm{U}_{0.71} \mathrm{Nd}_{0.29} \mathrm{O}_{2 \pm x}$ & $3725.3(2)$ & $3726.5(2)$ & - & This work \\
\hline $\mathrm{U}_{0.38} \mathrm{Nd}_{0.62} \mathrm{O}_{2 \pm x}$ & - & - & $3727.1(2)$ & This work \\
\hline
\end{tabular}

et al. [10]. Indeed, an overall agreement between reported values and Model \#1 is observed for $y=0.03$ and $y=0.13$. A slight deviation for the latter, meaning a slight amount of oxygen vacancies (i.e., Model \#3) can be argued. However, if one assumes an homogeneous Nd content in both phases instead of two different ones as described by Dottavio et al. [10], a better agreement with a deviation very close to the XAS result uncertainty is obtained. The absence of measurable hypostoichiometry suggests that the miscibility gap is not observed in our samples up to $\mathrm{y}=0.2$, contradicting the previously reported $\mathrm{y}=0.04$ value [10]. An important deviation from Model \#1 is clearly visible for the reported sample containing around $10 \%$ of $\mathrm{Nd}$, which is not the case in our measurement. Indeed, results reported by Dottavio et al. [10] indicate the presence of about $8 \%$ of oxygen vacancies while our sample demonstrates a pure $\mathrm{U}^{5+}$ compensation mechanism. Such a reported amount of oxygen vacancies is obtained by considering two different $\mathrm{Nd}$ content values for the two reported phases. If one assumes again an homogeneous $\mathrm{Nd}$ content for both phases, a better agreement is found with a $3 \%$ reduction of the oxygen vacancy content. This remains insufficient to consider their sample solely in line with Model \#1. However, their sample is not

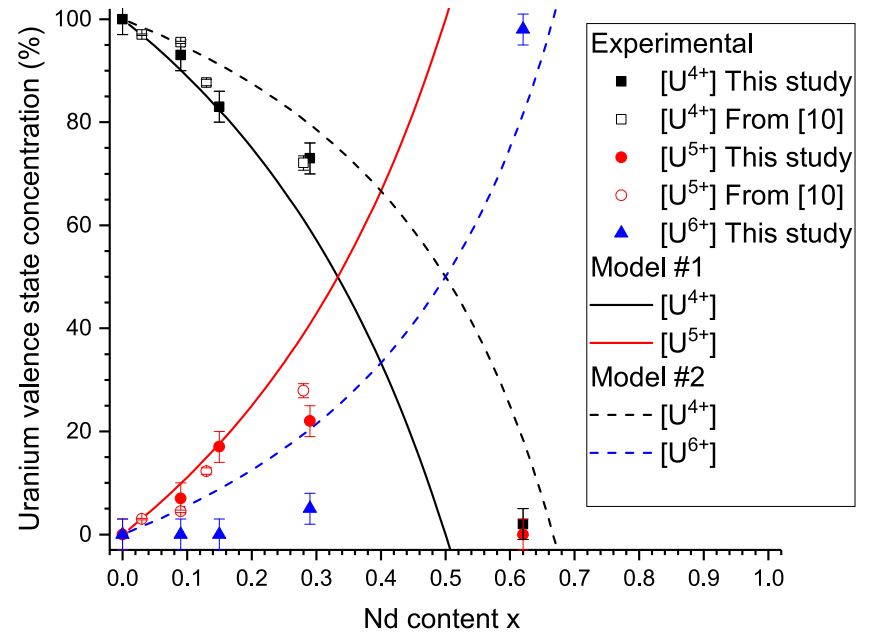

Fig. 3. Uranium valence state relative concentrations deduced from factor analysis (full symbols) and their expected evolution (full lines) according to two different models of charge compensation mechanism. The values published by Dottavio et al. [10] deduced from X-ray Diffraction with subsequent Rietveld refinement (empty symbols) are also shown for comparison.

Table 3

Valence concentrations [U4+], [U5+] and [U6+] in \% of $U$ as deduced from factor analysis. Uncertainties are about $3 \%$.

\begin{tabular}{llll}
\hline Sample & {$\left[\mathrm{U}^{4+}\right]$} & {$\left[\mathrm{U}^{5+}\right]$} & {$\left[\mathrm{U}^{6+}\right]$} \\
\hline $\mathrm{U}_{0.91} \mathrm{Nd}_{0.09} \mathrm{O}_{2 \pm x}$ & $93 \%$ & $7 \%$ & $0 \%$ \\
$\mathrm{U}_{0.85} \mathrm{Nd}_{0.15} \mathrm{O}_{2 \pm x}$ & $83 \%$ & $17 \%$ & $0 \%$ \\
$\mathrm{U}_{0.71} \mathrm{Nd}_{0.29} \mathrm{O}_{2 \pm x}$ & $73 \%$ & $22 \%$ & $5 \%$ \\
$\mathrm{U}_{0.38} \mathrm{Nd}_{0.62} \mathrm{O}_{2 \pm x}$ & $2 \%$ & $0 \%$ & $98 \%$ \\
\hline
\end{tabular}

consistent with trends concerning the lattice parameter behavior of the two assumed phases and for the mass fraction of each phase. Thus, even if the observed disagreement is not surprising, it remains unexplained but could be the consequence of sample 
preparation quality.

The sample around $\mathrm{y}=0.3$ exhibits a substantial deviation from Model \#1. The presence of $\mathrm{U}^{5+}$ and $\mathrm{U}^{6+}$ valence states as detected by HERFD-XANES demonstrates that both Models \#1 and \#2 are competing in this case. A significant deviation of about $20 \%$ and $10 \%$ for Model \#1 and Model \#2 is observed, respectively. However, the experimental concentration of $\left[\mathrm{U}^{5+}\right]$ and $\left[\mathrm{U}^{6+}\right]$ are not sufficient to ensure overall stoichiometry. The presence of oxygen vacancies, that is within Model \#3, could compensate for the observed deviation, leading to a deduced $\mathrm{O} / \mathrm{M}$ ratio of 1.97 (1), thus in good agreement with the value reported in Ref. [10] and with the possible presence of two phases in our sample.

Finally, the $\mathrm{U}_{0.38} \mathrm{Nd}_{0.62} \mathrm{O}_{2 \pm x}$ sample does not agree with any of the three models. The Nd content is out of the natural limits of the Model \#1 of $\mathrm{y}=0.5$ and close to the $\mathrm{x}=0.66$ natural limit of Model \#2. Due to the possible high uncertainty in $U$ valence evaluation arising from the structural disagreement between references and the $\mathrm{U}_{0.38} \mathrm{Nd}_{0.62} \mathrm{O}_{2 \pm x}$ sample, it is difficult to draw a conclusion about which compensation mechanism is dominating without additional data.

However, three different stages can be, at least, extracted from our data. The first region at low $\mathrm{Nd}$ content shows $\mathrm{U}^{5+}$ formation only, in good agreement with similar results reported in $\mathrm{U}_{y} \mathrm{Gd}_{1-y} \mathrm{O}_{2}$ for $\mathrm{y}<0.14$ [28]. Then, the formation of oxygen vacancies is observed in addition to oxidation of $\mathrm{U}^{4+}$ to higher valence states. However, the presence of a slight amount of $\mathrm{U}^{6+}$ is surprising compared to what was already observed for $\mathrm{U}_{y} \mathrm{Pu}_{1-y} \mathrm{O}_{2-x}$ [11] and $\mathrm{U}_{y} \mathrm{Ce}_{1-y} \mathrm{O}_{2-x}$ [12]. At high $\mathrm{Nd}$ content, $\mathrm{U}^{6+}$ is formed, and $\mathrm{O}$ vacancies are also strongly expected.

All of these steps are easily understood when one assumes homogeneous repartitioning of $\mathrm{Nd}$ into the $\mathrm{UO}_{2}$ matrix, and oxygen vacancy affinity for two $\mathrm{Nd}$ atoms as first neighbor. Indeed, when the concentration of $\mathrm{Nd}$ is very low, the probability to find another $\mathrm{Nd}$ as first neighbors is low, and consequently, the formation of $\mathrm{U}^{5+}$ remains the only way to compensate the missing charge, since creating an oxygen vacancy or the formation of $\mathrm{U}^{6+}$ is expected to compensate for two neighboring Nd atoms. Hexavalent uranium $\mathrm{U}^{6+}$ is not observed in our case below $\mathrm{y}=0.2$, confirming that $\mathrm{U}^{6+}$ formation in a fluorite structure is probably energetically too expensive compared to the formation of two $\mathrm{U}^{5+}$ cations. This is in good agreement with the absence of $\mathrm{U}^{6+}$ in the early oxidation stages of $\mathrm{UO}_{2}$ where $\mathrm{U}^{4+} / \mathrm{U}^{5+}$ mixtures are reported in $\mathrm{U}_{4} \mathrm{O}_{9}$ and $\mathrm{U}_{3} \mathrm{O}_{7}$ [32], or in the cases of $\mathrm{U}_{1-y} \mathrm{Bi}_{y} \mathrm{O}_{2+x}$ and $\mathrm{U}_{1-y} \mathrm{La}_{y} \mathrm{O}_{2+x}$ where only $\mathrm{U}^{5+}$ formation is reported up to $\mathrm{y}=0.5$ [15] and $\mathrm{y}=0.4$, respectively [35]. These upper limits are about two times the value found for $\mathrm{Nd}$ doped $\mathrm{UO}_{2}$ and suggest that the dominating mechanism depends on the dopant nature.

Finally, when the Nd concentration increases, the probability to find two Nd atoms as first neighbors increases as well, leading to the competitive compensation mechanisms of forming one $\mathrm{V}_{O}$, two $\mathrm{U}^{5+}$ cations or one $\mathrm{U}^{6+}$ cation. Then, when the concentration of $\mathrm{Nd}$ is well above $\mathrm{y}=0.5, \mathrm{U}^{5+}$ is converted to $\mathrm{U}^{6+}$, with a possible formation of $\mathrm{V}_{O}$, as suggested by comparison to $\mathrm{U}_{0.40} \mathrm{Bi}_{0.60} \mathrm{O}_{1.95}$ [15]. However, both experimental and theoretical assessments are needed, especially in the $y=0.2-0.7$ concentration range, to confirm or deny these assumptions and give a complete understanding of the charge compensation mechanisms in the $\mathrm{U}_{1-y} \mathrm{Nd}_{y} \mathrm{O}_{2 \pm x}$ system. Moreover, the $\mathrm{U}_{1-y} \mathrm{Nd}_{y} \mathrm{O}_{2-x}$ and $\mathrm{U}_{1-y} \mathrm{Nd}_{y} \mathrm{O}_{2.00}$ phase formations must be clarified using, for example, RAMAN spectroscopy and electron microscopy. Indeed, XAS gives only indirect information, and the formation of oxygen vacancies is not necessarily the signature of the formation of these two phases in our samples.

\section{Conclusion}

Based on $\mathrm{U} \mathrm{M}_{4}$-edge HERFD-XANES analysis, assessment of the charge compensation mechanisms in $\mathrm{U}_{1-y} \mathrm{Nd}_{y} \mathrm{O}_{2 \pm x}$ is reported. When a $\mathrm{Nd}^{3+}$ cation is substituted into the fluorite lattice, the charge difference is compensated by the formation of $\mathrm{U}^{5+}$ cation below approximately $\mathrm{y}=0.2$. This is also observed in $\mathrm{U}_{1-y} \mathrm{Gd}_{y} \mathrm{O}_{2}$ in cases of similar dopant concentrations [30]. Then, between $\mathrm{y}=0.2-0.6, \quad \mathrm{U}^{5+}$ and $\mathrm{U}^{6+}$ cations and oxygen vacancy are competing mechanisms leading to a hypostoichiometric compound. Finally, the formation of $\mathrm{U}^{6+}$ dominates for $\mathrm{y}>0.6$.

\section{Acknowledgements}

The authors warmly thanks the MARS beamline at SOLEIL and the ID26 beamline at ESRF for their support and provision of beamtime. S.M.B. acknowledges support from the Swedish Research Council (research grant 2017-06465).

\section{References}

[1] B.J. Lewis, W.T. Thompson, F.C. Iglesias, 2.20-Fission product chemistry in oxide fuels, in: R.J.M. Konings (Ed.), Comprehensive Nuclear Materials vol. 2, Elsevier, Oxford, 2012, 515?546.

[2] D.D. Baron, L. Hallstadius, 2.19-Fuel performance of light water reactors (uranium oxide and MOX), in: R.J.M. Konings (Ed.), Comprehensive Nuclear Materials vol. 2, Elsevier, Oxford, 2012, 481?514.

[3] H. Kleykamp, J. Nucl. Mater. 131 (1985) 221.

[4] H. Kleykamp, J. Nucl. Mater. 206 (1993) 82.

[5] H.G. Diehl, C. Keller, J. Solid State Chem. 3 (1971) 621.

[6] C. Keller, A. Boroujjerdi, Inorganic Nuclear Chemistry 34 (1972) 1187.

[7] T. Ohmichi, S. Fukushima, A. Maeda, H. Watanabe, J. Nucl. Mater. 102 (1996) 40.

[8] L. Desgranges, Y. Pontillon, P. Matheron, M. Marcet, P. Simon, G. Guimbretière, F. Porcher, Inorg. Chem. 51 (2012) 9147.

[9] G. Dottavio, Y. Pontillon, L. Desgranges, R. Belin, J.-C. Richaud, J. Noirot, C. Valot, Prog. Nucl. Energy 72 (2014) 22.

[10] G. Dottavio, Y. Pontillon, L. Desgranges, C. Guéneau, R. Belin, J. Nucl. Mater. 458 (2015) 394.

[11] C. Guéneau, N. Dupin, B. Sundman, C. Martial, J.-C. Dumas, S. Gossé, S. Chatain, F.D. Bruycker, D. Manara, R.J.M. Konings, J. Nucl. Mater. 419 (2011) 145.

[12] D.I.R. Norris, P. Kay, J. Nucl. Mater. 116 (1983) 184.

[13] M.A. Denecke, 19-X-Ray spectroscopy in studies of the nuclear fuel cycle, in: J.A.V. Bokhoven, C. Lamberti (Eds.), X-Ray Absorption and X-Ray Emission Spectroscopy, John Wiley \& Sons, Ltd, 2016, pp. 523-559.

[14] K.O. Kvashnina, S.M. Butorin, P. Martin, P. Glatzel, Phys. Rev. Lett. 111 (2013) 253002.

[15] K. Popa, D. Prieur, D. Manara, M. Naji, J.-F. Vigier, P.M. Martin, O. Dieste Blanco, A.C. Scheinost, T. Prüßmann, T. Vitova, P.E. Raison, J. Somers, R.J.M. Konings, Dalton Trans. 45 (2016) 7847.

[16] M.R. Antonio, L. Soderholm, Chapter 28-X-ray absorption spectroscopy of the actinides, in: L.R. Morss, N.M. Edelstein, J. Fuger (Eds.), The Chemistry of the Actinide and Transactinide Elements, Springer Netherlands, 2006, pp. 3086-3198.

[17] A.L. Smith, P. Martin, D. Prieur, A.C. Scheinost, P.E. Raison, A.K. Cheetham, R.J.M. Konings, Inorg. Chem. 55 (2016) 1569.

[18] Y. Podkovyrina, I. Pidchenko, T. Prüßmann, S. Bahl, J. Göttlicher, A. Soltatov, T. Vitova, J. Phys. Conf. 712 (2016) 012092.

[19] R. Vauchy, A.-C. Robisson, P.M. Martin, R.C. Belin, L. Aufore, A.C. Scheinost, F. Hodaj, J. Nucl. Mater. 456 (2015) 115.

[20] R. Vauchy, R.C. Belin, A.-C. Robisson, F. Lebreton, L. Aufore, A.C. Scheinost, P.M. Martin, Inorg. Chem. 55 (2016) 2123.

[21] D. Prieur, P.M. Baldo, A. Jankowiak, E. Gavilan, A.C. Scheinost, N. Herlet, P. Dehaudt, P. Blanchart, Inorg. Chem. 50 (2011) 12437.

[22] D. Prieur, P. Martin, F. Lebreton, T. Delahaye, D. Banerjee, A.C. Scheinost, A. Jankowiak, J. Nucl. Mater. 434 (2013) 7.

[23] J.-F. Vigier, P.M. Martin, L. Martel, D. Prieur, A.C. Scheinost, J. Somers, Inorg. Chem. 54 (2015) 5358.

[24] F. Lebreton, D. Horlait, R. Caraballo, P.M. Martin, A.C. Scheinost, A. Rossberg, C. Jégou, T. Delahaye, Inorg. Chem. 54 (2015) 9749.

[25] B. Sitaud, P.L. Solari, S. Schlutig, I. Llorens, H. Hermange, J. Nucl. Mater. 425 (2012) 238.

[26] C. Gauthier, V.A. Solé, R. Signorato, J. Goulon, E. Moguiline, J. Synchrotron Radiat. 6 (1999) 164

[27] K.O. Kvashnina, A.C. Scheinost, J. Synchrotron Radiat. 23 (2016) 836.

[28] B. Ravel, M. Newville, J. Synchrotron Radiat. 12 (2005) 537. 
[29] A. Rossberg, K.-U. Ulrich, S. Weiss, S. Tsushima, T. Hiemstra, A.C. Scheinost, Environ. Sci. Technol. 43 (2009) 1400.

[30] R. Bès, J. Pakarinen, A. Baena, S. Conradson, M. Verwerft, F. Tuomisto, J. Nucl. Mater. 489 (2017) 9

[31] R. Bès, M. Rivenet, P.-L. Solari, K.O. Kvashnina, A.C. Scheinost, P.M. Martin, Inorg. Chem. 55 (2016) 4260.

[32] G. Leinders, R. Bès, J. Pakarinen, K. Kvashnina, M. Verwerft, Inorg. Chem. 56 (2017) 6784
[33] T. Vitova, J.C. Green, R.G. Denning, M. Löble, K. Kvashnina, J.J. Kas, K. Jorissen, J. Rehr, T. Malcherek, M.A. Denecke, Inorg. Chem. 54 (2015) 174

[34] I. Pidchenko, K.O. Kvashnina, T. Yokosawa, N. Finck, S. Bahl, D. Schild, R. Polly E. Bohnert, A. Rossberg, J. Göttlicher, K. Dardenne, J. Rothe, T. Schäfer H. Geckeis, T. Vitova, Environ. Sci. Technol. 51 (2017) 2217.

[35] S.M. Butorin, K.O. Kvashnina, D. Prieur, M. Rivenet, P.M. Martin, Chem. Commun. 53 (2017) 115. 